\title{
REVIEW
}

\section{Environmental effects on spatial population dynamics and synchrony: lessons from northern ecosystems}

\author{
Ivar Herfindal ${ }^{1, *}$, Aline Magdalena Lee ${ }^{1}$, Jonatan F. Marquez ${ }^{1}$, Mathilde Le Moullec ${ }^{1}$, \\ Bart Peeters ${ }^{1}$, Brage Bremset Hansen ${ }^{1}$, John-André Henden ${ }^{2}$, Bernt-Erik Sæther ${ }^{1}$ \\ ${ }^{1}$ Centre for Biodiversity Dynamics, Department of Biology, Norwegian University of Science and Technology, \\ Trondheim 7491, Norway \\ ${ }^{2}$ Department of Arctic and Marine Biology, The Arctic University of Tromsø, Tromsø 9019, Norway
}

\begin{abstract}
Environmental variation in time and space generates complex patterns in the spatial structure of temporally covarying populations. Accounting for spatial population structure is important for sustainable management and harvest, but there is a need for a better understanding of the many mechanisms affecting the spatial structure of populations. In the large-scale research project SUSTAIN, detailed long-term data from several taxa within the boreal and Arctic ecosystems were used to address key research questions about spatial population structure. Here, we synthesise the main findings from these studies. Because nearby populations experience similar environmental variation, populations close to each other show more correlated dynamics than those at greater distances. However, several mechanisms can affect the extent of such spatial population synchrony, and we point to some similarities across systems that can explain the observed discrepancy between the spatial structure of the environment and that of population dynamics. We discuss the consequences of these findings for the practical management of species in a changing environment and the need for further research on how populations and ecosystems are affected by the spatial structure of the environment.
\end{abstract}

KEY WORDS: Spatial synchrony - Environmental variation - Population dynamics - Harvest strategies $\cdot$ Climate change

\section{INTRODUCTION}

The great majority of species exist in several populations or subpopulations spread out in space. Spatially separated populations often show differences in phenotypes, life history traits, vital rates and temporal variation in population size. The study of spatial structure in population dynamics has a long history (Elton 1924, MacArthur 1972, Levin 1992). One theoretical framework that has been used to unravel the causes and consequences of spatial population structure is the theory of population synchrony (Moran

\footnotetext{
*Corresponding author: ivar.herfindal@ntnu.no
}

1953, Koenig 2002), defined as spatial correlation in the fluctuations of size or density of different populations (Bjørnstad et al. 1999, Liebhold et al. 2004). The theory of population synchrony differs from the wellknown metapopulation theory (Levin 1974, Hanski 1999) in its main focus and approach. In metapopulation theory, the emphasis is on how intrinsic features of subpopulations, such as their size and rates of emigration and immigration, affect local and regional population dynamics (Hanski 1999), whereas spatial population synchrony theory typically emphasises the role of extrinsic factors and the environment (Moran

() The authors 2022. Open Access under Creative Commons by Attribution Licence. Use, distribution and reproduction are unrestricted. Authors and original publication must be credited. 
1953, Royama 1992). Later extensions of these 2 approaches (e.g. Lande et al. 1999, Keymer et al. 2000, Sæether et al. 2007) have brought them closer, but they still represent different angles to understand the causes and consequences of spatially structured populations.

The term environment can have a variety of meanings in ecological research but often refers to abiotic factors such as temperature, humidity, salinity or $\mathrm{pH}$ (Begon et al. 2006). Environmental variation is among the most important drivers of dynamics in population size, vital rates and life history traits (Stenseth et al. 2002). The environment itself has a strong spatial structure, measured as spatial autocorrelation in more persistent characteristics such as habitat or climate, or as temporal variation in, for example, weather (Koenig 2002, Herfindal et al. 2022 in this Special). As a result, we often observe analogous spatial scaling of biological processes and the environment (Wiens 1989, Kareiva et al. 1990, Levin 1992, Myers et al. 1997, Koenig 1999), and environmental autocorrelation is a major driver of population synchrony (Liebhold et al. 2004). For instance, the Moran theorem (Moran 1953, Royama 1992) predicts that the correlation in the dynamics of 2 populations subject to a loglinear form of density regulation should be equal to the environmental correlation between the corresponding locations. This link between the spatial structure of environmental variation and spatial population synchrony makes the theory of population synchrony a promising concept to gain better insight into processes affecting spatial population dynamics in a world experiencing rapid environmental changes (Koenig 2002, Liebhold et al. 2004, Hansen et al. 2020).

Synchrony in population dynamics is often weaker and has a shorter spatial scale than synchrony in the environment (Benton et al. 2001, Koenig 2001, Hansen et al. 2020). This can occur because central assumptions in the Moran theorem, such as the assumption that log-linear density dependence is similar among populations (Royama 1992), rarely are met in natural systems. Such deviations from the Moran theorem can have great impact on the observed population synchrony (Engen \& Sæther 2005). In addition, heterogeneity in demographic rates, such as survival and recruitment, among populations of a species is affected by factors such as interspecific interactions, climate, or habitat and resource availability (Ranta et al. 1999, Paradis et al. 2000b, Engen \& Sæther 2005, Lande et al. 2014, Gamelon et al. 2020). This can lead to the same environmental condition having a contrasting effect on the growth of different populations of the same species. Environmental variables also differ in their spatial structure
(Koenig 2002), which may vary over the year (Chevalier et al. 2015, Herfindal et al. 2022), which can further contribute to increased heterogeneity in dynamics among populations. When comparing spatial population structure among species, heterogeneity in population processes can become even more important, as this may vary considerably even among closely related species inhabiting the same area (Bjørkvoll et al. 2012).

Disentangling the role of such heterogeneity in the environment and among populations is central for understanding the mechanisms causing spatial structuring of populations. The environment is changing, and this is likely to affect spatial population synchrony (Defriez et al. 2016, Black et al. 2018, Kahilainen et al. 2018). Climate change can affect population synchrony by causing changes in the spatial structure of the environment, as well as by changing how local populations respond to environmental variation (Hansen et al. 2020). Hence, even if climate change is similar over large areas, population synchrony can change because some populations are more strongly impacted than others due to differences in local conditions affecting, for example, carrying capacity or the strength of density dependence (Engen \& Sæther 2005). Understanding climate change effects on spatial population synchrony thus requires knowledge about heterogeneity in local demographic processes.

Knowledge about spatial population structure is crucial for sustainable management and conservation. For instance, the size of management units is often based on the area requirements of individuals (Linnell et al. 2001, Zannése et al. 2006), which is closely related to the abundance of a species within a given area (Fretwell \& Lucas 1969). Local and regional extinction risks are also affected by the spatial heterogeneity in environmental variation (Heino et al. 1997). This occurs because when environmental fluctuations are correlated over large distances, population fluctuations will tend to be synchronised over similar distances (Ranta et al. 1997, Pascual \& Levin 1999). This increases the likelihood of local populations across large areas being at low abundance simultaneously. In a more heterogeneous environment, different populations tend to experience unfavourable conditions in different years, causing population dynamics to be less synchronous. Local populations are then more likely to be rescued from extirpation through immigration from nearby highdensity populations (Heino et al. 1997). Management of harvested species should acknowledge such mechanisms. For instance, if harvesting quotas are set similarly over large areas, local populations that 
are experiencing low abundances compared to the overall mean will experience overharvest (Jonzen et al. 2001), which increases the risk of local extinction and loss of genetic variation.

Despite recent theoretical advances and empirical evidence of spatial population synchrony in a wide range of species, we still have much to learn about the mechanisms and consequences of population synchrony in real systems (Hansen et al. 2020). Because of the numerous and complex factors involved in determining how spatially structured environments affect populations, studying this topic is challenging with respect to both statistical modelling and data requirements. Although spatially structured time series of both populations and their environments are increasingly becoming available through open-data facilities, they are often the result of different sampling protocols where estimates of population abundances can be difficult to compare. The main aim of the SUSTAIN research project was to determine how climate change, in combination with other anthropogenic stressors, affects harvested boreal and Arctic ecosystems experiencing different environmental variation. The second aim was to assess how management strategies could be improved to ensure sustainable exploitation and resilience. The project involved several ecological research groups working with different ecosystems, which made it possible to compile data that allowed investigation of the complexity of population dynamics in spatially structured environments to address the ambitious aims of the project. Below, we synthesise the results from this compilation of empirical data from different study systems to address specific questions about population synchrony.

\section{CASE STUDIES OF SPATIAL POPULATION SYNCHRONY}

\subsection{Influences on the relationship between environmental variation and population synchrony}

Environmental effects on population dynamics and life history traits often differ among populations of the same species (Mysterud et al. 2002, Herfindal et al. 2006, Nielsen et al. 2012, Tveraa et al. 2013, Henden et al. 2022 in this Special). This can weaken the synchronising effect of environmental variation even if the environment itself is synchronised over large distances. Analysing such mechanisms in harvested species is challenging because abundance data often come from harvest bags, which rarely are informa- tive for population dynamics (Ranta et al. 2008). However, additional data on life history traits that are also often collected during harvest (Solberg et al. 2006) can still provide insight into the environmental influence on population synchrony.

Juvenile body mass is closely related to environmental conditions in the year of birth (Eberhardt 2002, Mysterud 2006) and has lifetime consequences for survival and reproduction (Lindström 1999, Markussen et al. 2018, 2019, Pigeon et al. 2019). Herfindal et al. (2020) explored how environmental variation affects population synchrony by using extensive spatiotemporal data on juvenile body mass from moose and reindeer across Norway. May and June temperature had the strongest synchronising effect on juvenile body mass for reindeer and moose, respectively, because of a consistent effect on juvenile body mass in all populations. In addition, temperature showed high spatial synchrony compared to precipitation, which highlights the low synchronising potential of precipitation even if precipitation in parts of the year was a good predictor for body mass variation. When there was high heterogeneity among populations in how juvenile body mass was affected by a weather variable, it had a weak synchronising effect. The results show that the spatial structure of the environment, the strength of the relationship between environmental variation and population dynamics, and the extent of heterogeneity in population responses to environmental variation must be assessed to understand how weather synchronises population dynamics. In many species, survival and reproduction are affected by conditions experienced at different times of the year (Israelsen et al. 2020, Layton-Matthews et al. 2020). Detecting the critical period for variation in key life history traits (e.g. van de Pol \& Cockburn 2011) is thus required to understand the mechanisms that create spatial structure in population dynamics.

\subsection{Intra- and interspecific variation in the spatial scale of population synchrony within an environment}

A logical consequence of the Moran effect would be that species living in the same environment, and thus experiencing the same environmental variation, should show similar spatial scales of population synchrony. However, a recent long-term study of fish species in the Barents Sea demonstrated that this is not necessarily the case (Marquez et al. 2019). Estimated spatial scaling parameters for both population abundance and population growth rate varied more 
than 2-fold among the 8 species studied. Several factors can cause such differences in spatial structure among species, including different levels of dispersal (Lande et al. 1999), interspecific competition (Jarillo et al. 2018, Lee et al. 2020), trophic interactions (Kent et al. 2007, Jarillo et al. 2020), habitat preference (Pandit et al. 2016, Paradis et al. 2000a), foraging behaviours (Robertson et al. 2015) and sensitivity to different environmental variables (Lahoz-Monfort et al. 2011, Herfindal et al. 2020).

In the Barents Sea, the observed interspecific variation in the scale of spatial synchrony in abundance was related to the species' life history traits (Marquez et al. 2019). Species with short generation times and high population growth and mortality rates, qualities characteristic of fast-lived species, were associated with shorter synchrony scales, while species with long generation times and lower growth and mortality rates showed synchrony over greater distances. This relationship between life history and scaling of synchrony was suggested to be driven by densityregulated processes. Species with fast life histories tend to show stronger density regulation than species with slow life histories (Herrando-Pérez et al. 2012). Strong density regulation causes population abundances to return more quickly to equilibrium after a disturbance. Thus, fluctuations in abundance caused by localised environmental fluctuations are dampened quickly, providing less opportunity for them to ripple far through the system via dispersal, resulting in a weak synchrony among distant locations. This is in accordance with theoretical results (Lande et al. 1999, Engen 2017). In contrast, dispersal in a weakly density regulated population would be less hindered by local density, and this is expected to increase the extent of spatial synchrony beyond the spatial scaling of environmental synchrony (Engen 2017).

Within a population, different age groups can disperse and respond to environmental variability differently. For example, adult individuals tend to be more resistant against adverse environmental conditions and predation pressure than juveniles (Kuo et al. 2016). Thus, different age groups of the same populations could show different patterns of spatial autocorrelation (Engen et al. 2018b). Indeed, analyses of the Barents Sea fish community confirm this, with different patterns found in different species. Spatial autocorrelation increased with age in cod, decreased with age in beaked redfish and remained constant through life in haddock (Marquez et al. 2021). This has implications for harvesting practices that change population age structure, since harvesting could alter the spatial structure and synchrony of ecologically and economically important species, making some populations more prone to overharvest and extinction (Kuo et al. 2016).

\subsection{Spatial heterogeneity in climate effects desynchronises plant growth}

The importance of dispersal on population synchrony in animals is often difficult to disentangle from environmental factors (Hopson \& Fox 2019). However, in sedentary species such as perennial plants, this problem is eliminated by studying time series of performance measures such as growth from the same individuals. Accordingly, Le Moullec et al. (2020) studied the synchrony in ring growth of the dwarf shrub Salix polaris in 8 sites across Svalbard. Ring growth in this species reflects the annual community-level biomass production of vascular plants and can thus serve as a good indicator of temporal fluctuations in the spatial structure of primary productivity in general (Le Moullec et al. 2019a). Since weather and spatial variation in climate often affect animal populations indirectly by influencing their foraging resources, spatial synchrony in the ring growth of indicator species, such as $S$. polaris in high Arctic ecosystems, can provide a better understanding of the underlying mechanisms driving differences in the spatial synchrony of the environment and harvested herbivores.

Summer temperature is a well-known driver of Arctic plant growth, and its rapid warming trend has led to an overall greening of the Arctic (van der Wal \& Stien 2014, Myers-Smith et al. 2015). Concurrently, increased winter temperature has resulted in more frequent occurrences of rain-on-snow events during winter particularly in coastal areas, which causes the formation of basal ice layers that often encapsulate the vegetation in the field layer (AMAP 2017, Peeters et al. 2019). Le Moullec et al. (2020) found that summer temperature was the main driver of vegetative growth and explained part of the shrub growth synchrony across the archipelago. More surprisingly, winter precipitation had a negative effect on ring growth in some coastal sites where winter precipitation frequently comes as rain. This caused increased spatial heterogeneity in the system (Le Moullec et al. 2020). Similar spatial variation in the effects of winter weather was found in Svalbard reindeer (see Section 2.4), which suggests that spatial heterogeneity in environmental variables under rapid change can reduce population synchrony across trophic levels. Although rain-on-snow events are more prevalent in 
coastal than inland regions, they are strongly synchronised across the landscape (Peeters et al. 2019). The increased frequency of rain-on-snow events across the Arctic (Putkonen \& Roe 2003, Bintanja \& Andry 2017) could therefore change the relative importance of seasons in shaping the spatio-temporal dynamics of species communities in the near future.

\subsection{Spatial variation in climate change effects decouple local population dynamics}

Climate change can affect population synchrony, for instance by affecting the spatial autocorrelation in weather (Dallas et al. 2020, Allen \& Lockwood 2021). Because environmental effects on population dynamics are often density dependent, changes in spatial heterogeneity in such processes can decouple population dynamics in space (Engen \& Sæther 2005, Anders \& Post 2006). Hansen et al. (2019) investigated the role of the Moran effect on the population synchrony of 10 populations of wild Svalbard reindeer Rangifer tarandus platyrhynchus in the high Arctic and how this has changed due to recent climate change.

Warmer and longer summers have in general increased the carrying capacity and abundance of reindeer populations (Le Moullec et al. 2019b), while fluctuations in annual population size are largely driven by the density-dependent effects of rain-on-snow events (Hansen et al. 2019). Rain on snow causes the formation of ice on the ground, limiting food availability during winter and reducing survival and reproduction (Hansen et al. 2011, Stien et al. 2012, Albon et al. 2017) and, thereby, population growth (Forchhammer \& Boertmann 1993, Hansen et al. 2011, 2019). Accordingly, spatially autocorrelated fluctuations in rain-on-snow events synchronised reindeer dynamics across large parts of Svalbard, while spatial variation in the increase in frequency of these weather events contributed to the divergence of local population trends. This was evident from the comparison of 2 well-monitored reindeer populations, where the coastal population was subject to a stronger temporal increase in the frequency of rain on snow and a stronger density-dependent effect of such conditions on population growth rates than the inland population. On the other hand, the coastal population experienced weaker summer warming and showed the weakest positive response to summer temperatures. In sum, only the inland population showed a positive abundance trend. These results imply that the environmentally induced Moran effect can be buffered by spatial heterogeneity in the same environ- mental drivers, potentially averaging out the impacts of global warming at larger spatial scales (Hansen et al. 2019).

\subsection{Impacts of climate change and overexploitation on spatial population structure}

To understand the combined effects of past overexploitation and ongoing climate change on spatial population dynamics, Peeters et al. (2020) adopted a landscape genetics approach on the island-dwelling Svalbard reindeer. In contrast to the migratory behaviour in most reindeer and caribou subspecies, Svalbard reindeer are non-migratory and have small home ranges (Tyler 1987), which was evident from the strong genetic differentiation between some populations that were only tens of kilometres apart (see also Côté et al. 2002). Across the archipelago, the strong population genetic structure was partly attributed to historical overexploitation. Unregulated harvest was banned in 1925 but had already led to extirpations of reindeer across large parts of Svalbard. The few remaining and critically small populations gradually recolonised the former distribution range, partly mediated by reintroductions (Le Moullec et al. 2019b). Landscape genetics analyses further indicated that the spatial population structure was determined by restricted dispersal across steep mountains, glaciers, fjords and open sea between islands (Peeters et al. 2020). Furthermore, the seasonal occurrence of sea ice facilitated dispersal and was a key driver of gene flow and source-sink dynamics among populations. Due to global warming and the strong oceanographic gradient in sea surface temperatures around Svalbard, the increased rarity of sea ice has already limited the genetic mixture between neighbouring reindeer populations along the west coast.

Climate change is of particular concern for the population connectivity of high Arctic terrestrial species that depend on dispersal across sea ice (Post et al. 2013). The lack of sea ice as a dispersal corridor will likely decrease recolonisation probabilities and increase the risk of inbreeding and loss of genetic diversity, particularly in small and isolated populations (Saccheri et al. 1998). Peeters et al. (2020) demonstrated how population genetic structure and connectivity can be influenced by interactions of past (overexploitation) and ongoing (climate change) anthropogenic drivers. Climate change and harvesting can thus strongly influence the evolutionary potential and persistence of species through effects on population connectivity and spatial genetic struc- 
ture. Moreover, the loss of connectivity will reduce immigration rates from nearby high-density populations and increase the extirpation risk of small populations (Heino et al. 1997). Populations with strong spatial synchrony in their environmental drivers are therefore expected to be at particularly high risk.

\subsection{Implementing spatial structure in population dynamics into practical management}

It can be challenging to sustainably manage and harvest species with a strong spatial structure. If dynamics are not synchronised or are driven by different factors in different subpopulations, harvesting strategies must be locally adapted. In addition to the ecological challenges of disentangling the spatial heterogeneity of how different drivers affect population dynamics, it also becomes challenging to communicate such strategies to end users. This is particularly true because management of natural resources often involves a top-down process where stakeholders and end users have limited possibilities to contribute to practical management actions (Redpath et al. 2013). This is unfortunate, as these groups often have local hands-on knowledge about biological processes based on experience and perceptions from extensive use of the systems (Ims \& Yoccoz 2017). Moreover, when the need for management-relevant knowledge is urgent, it can be efficient to involve stakeholders in the research process to foster collaborative understanding of management needs and to increase legitimacy and decision support. One approach to ensure stakeholder involvement is the strategic foresight protocol (SFP) (Cook et al. 2014, Hamel et al. 2022 in this Special).

Developing management strategies that account for spatially structured environments warrants spatially explicit data on the focal species and the environment and other important drivers (Ims \& Yoccoz 2017). While such data are rare, the willow ptarmigan Lagopus lagopus in the boreal and low Arctic ecosystem of Finnmark, northern Norway, represents a system where such food web data are available (Henden et al. 2020). The willow ptarmigan has historically displayed large periodic fluctuations in abundance. In recent decades, population trends have been negative in large parts of its worldwide distribution (Henden et al. 2011, Fuglei et al. 2020). As a result, hunting has become more regulated, requiring better knowledge about mechanisms causing local and regional population fluctuations (Henden et al. 2017).
To obtain a better knowledge foundation for the management of willow ptarmigan in Finnmark, stakeholders were invited to participate in an SFP approach (Henden et al. 2020). Because of the recent red listing of ptarmigan in Norway (Henriksen \& Hilmo 2015) and because many stakeholders are well acquainted with previous research on willow ptarmigan from Scandinavia, many stakeholders revealed similar views on urgent research needs to better understand past dynamics and trends. Interestingly, several stakeholders expressed a need for near-term forecasts of the population state to better prepare for and adapt harvest regulations, and thereby provide a useful tool for adaptive management of willow ptarmigan in this region (Henden et al. 2020). The main drivers highlighted through these discussions included changes in food web dynamics and predation pressure, local climate, changed seasonality and harvesting pressure (Henden et al. 2021). As expected, several of these factors varied spatially within the region (e.g. Ims et al. 2019, Vindstad et al. 2019); hence, a spatio-temporal model of ptarmigan dynamics was developed. This model revealed high spatial synchrony in the ptarmigan dynamics. However, spatial heterogeneity in the dynamics of important drivers such as moth outbreaks (causing defoliation of birch forest and impacting ptarmigan food availability) and harvesting was important in explaining local dynamics of ptarmigan populations. Importantly, the accuracy of the model in predicting the next year's abundance of willow ptarmigan therefore varied in space. This suggests that caution should be taken when using aggregated models that assume homogeneity of responses over larger areas. Doing so may result in imprecise management actions in areas where other mechanisms may constitute key drivers or where the drivers of population dynamics are uncorrelated with the drivers from where the model is derived. By incorporating a spatially explicit model for willow ptarmigan dynamics, managers now have a tool for making spatially structured management plans.

\section{DISCUSSION AND FUTURE PROSPECTS}

The link between the spatial structure of populations and their environment has been described in multiple taxa (Liebhold et al. 2004, Walter et al. 2017). The case studies from the SUSTAIN project presented here confirm such a general pattern but also show that spatial population synchrony is typically weaker than environmental synchrony. Heterogeneity in how local populations respond to environmental variation, 
such as weather, seems to constitute a key mechanism for the discrepancy between the spatial structures of the environment and populations. However, the case studies did not investigate other synchronising mechanisms, such as trophic interactions or dispersal. There are few empirical studies on such mechanisms on spatial population synchrony, but these do suggest that, for instance, a high level of dispersal or the presence of a nomadic predator tends to increase, rather than decrease, population synchrony (Ims \& Andreassen 2000, Benton et al. 2001, Abbott 2011, Anderson et al. 2018). Accordingly, it seems likely that spatial heterogeneity in population responses to environmental variation is the main reason why we observe a weaker synchrony in population dynamics than in the environment.

Many factors can cause heterogeneity in the relationship between population growth and weather or climate. Variation in the strength of density dependence among populations will result in different dynamics for populations experiencing similar environmental variation (Engen \& Sæther 2005, Sæther et al. 2007). Spatial variation in habitat or climate conditions can affect how weather impacts, for instance, foraging conditions (Mysterud et al. 2001, 2002), which influences survival and recruitment (Hansen et al. 2011). In addition, even nearby populations often experience different levels of interspecific interactions which also affect population dynamics (Gamelon et al. 2020). Theoretical results obtained from other studies in the SUSTAIN project (Jarillo et al. 2018, 2020, Lee et al. 2020) strongly indicate that climate change will accentuate the necessity for implementing the effects of harvesting on spatial synchrony in the dynamics of interacting species. Knowledge about such potential changes in the spatial distribution of abundances will probably be a prerequisite for sustainable ecosystembased management.

The fact that there were strong differences in the spatial structure of marine species inhabiting the same habitat (Marquez et al. 2019), and thus experiencing similar spatial structure of the environment, supports the notion that spatial population synchrony is not only affected by the environment but also by internal species-specific mechanisms such as the strength of density dependence and life history strategies. Also, here, estimates of spatial population synchrony in marine fish (Marquez et al. 2019) were considerably lower than the estimates of spatial synchrony in the environment that have been obtained for the same system (Herfindal et al. 2022). This suggests that even in marine systems with few limitations in the flow of individuals and nutrients, which would support highly synchronised population dynamics over large spatial scales (Steele 1985, Steele \& Henderson 1994, Carr et al. 2003), there is a strong spatial population structure (Myers et al. 1995, 1997, Marquez et al. 2019).

How spatial structure in population dynamics affects local and regional population processes can be hard to assess empirically. However, modern genetic tools combined with models for spatial connectivity provided insight into the genetic consequences of climate change and past overexploitation on the spatial structure of Svalbard reindeer (Peeters et al. 2020). The consequences of climate change on connectivity between populations can be particularly critical for small populations (Lande 1998). However, climate change can also affect spatial structure through other mechanisms in addition to connectivity between populations. The plant and reindeer studies from Svalbard showed that the spatial variation in how climate change affected local conditions increased the heterogeneity in population responses to weather (Le Moullec et al. 2020, Hansen et al. 2019). This occurs even if climate change, measured as an increase in temperature or precipitation, is similar over large areas. The implications of weather or climate trends for important environmental conditions, such as snow accumulation and basal ice formation, show large spatial variation (Peeters et al. 2019). The result is an increased spatial heterogeneity in the environmental conditions experienced by populations in a given year, which decreases population synchrony (Engen \& Sæther 2005, Sæther et al. 2007, Hansen et al. 2019).

The combined results from the Svalbard reindeer case studies (Hansen et al. 2019, Peeters et al. 2020) illustrate the importance of understanding and accounting for spatial variation in the effects of environmental changes on both local population dynamics and connectivity between populations. This is highly relevant for the management of harvested populations where spatial variation in harvest intensity can modify both the spatial scale of population synchrony (Engen et al. 2018a,b, Jarillo et al. 2018) and source-sink dynamics (Péron et al. 2012). Overall, climate change can affect population synchrony and spatial structure through many mechanisms (Defriez et al. 2016, Koenig \& Liebhold 2016, Black et al. 2018, Kahilainen et al. 2018), and further research on climate change effects on spatio-temporal population patterns across systems and taxa is needed to provide general guidelines for sustainable management of populations and species.

Sustainable management of species in spatially structured environments must acknowledge the driv- 
ers of local population dynamics and be able to act at the appropriate spatial scale if local abundances become critically low. This requires in-depth knowledge about local and regional ecological processes affecting spatio-temporal patterns of population size (Henden et al. 2020, Mellard et al. 2022 in this Special). Knowledge about the harvesting itself, how it varies in time and space and how it affects the spatial patterns of population dynamics is also required (Engen et al. 2018a, Lee et al. 2022 in this Special). Such knowledge is not found in standard ecological data, and can only be achieved through a strong involvement of stakeholders and end users in the development of harvest strategies (Henden et al. 2020, Hamel et al. 2022). This illustrates one of the major challenges for research and management of species in spatially structured environments: the need for spatially explicit time series from harvesting practices or other management actions, environmental conditions and populations. Moreover, data from species other than those of focal management interest are also important (Anderwald et al. 2015, Henden et al. 2021, Lee \& Sæther 2022 in this Special), because species do not live in isolation but co-exist and interact with other species (Gamelon et al. 2020, Mellard et al. 2022).

Obtaining the data needed for sustainable management of species and ecosystems under climate change is resource demanding (Henden et al. 2020). If we want to account for spatial processes, we need to reconsider how we design ecosystem monitoring programmes. In addition to assessing short- and long-term changes across environmental gradients (Ims et al. 2007, Ims \& Yoccoz 2017, Halbritter et al. 2020, Negret et al. 2020), spatial replicates, e.g. within a habitat type or climatic condition, are needed. Knowing the spatial structure of biological processes can aid in both the planning and implementation of monitoring as well as the interpretation and generalisation of results (Yoccoz et al. 2001, Negret et al. 2020, Lee et al. 2022). Failing to account for the spatial structure of the environment and populations can have important consequences, for instance by generating biased estimates of the effectiveness of conservation actions (Negret et al. 2020). Although ecological data from different research or monitoring programmes are increasingly being compiled and made available (Culina et al. 2018, 2021), systematic monitoring of key species at different trophic levels from the same system is more suitable for gaining an understanding of the complex spatiotemporal dynamics caused by the environment, species interactions and human impacts (Ims \& Yoccoz 2017). One important reason is that systematically sampled data over large areas make it easier to ad- dress uncertainties due to observation errors (Buckland et al. 2007). Biased and imprecise estimates of demographic rates due to sampling error affect estimates of the spatial structure of the species (Lillegård et al. 2005). Such spatial biases can greatly affect how efficient and precise management strategies are (Aanes et al. 2002).

Acknowledgements. In addition to financial support from the Research Council of Norway (RCN) to the project SUSTAIN (project no. 244647), research was supported through the RCN Centres of Excellence funding scheme (project no. 223257), and B.B.H. was additionally supported by RCN project no. 276080 .

\section{LITERATURE CITED}

Aanes S, Engen S, Sæther BE, Willebrand T, Marcström V (2002) Sustainable harvesting strategies of willow ptarmigan in a fluctuating environment. Ecol Appl 12:281-290

Abbott KC (2011) A dispersal-induced paradox: synchrony and stability in stochastic metapopulations. Ecol Lett 14: 1158-1169

Albon SD, Irvine RJ, Halvorsen O, Langvatn R and others (2017) Contrasting effects of summer and winter warming on body mass explain population dynamics in a food-limited Arctic herbivore. Glob Change Biol 23:1374-1389

Allen MC, Lockwood JL (2021) Mapping shifts in spatial synchrony in North American grassland birds to inform conservation planning. Conserv Biol 35:1029-1038

AMAP (Arctic Monitoring and Assessment Programme) (2017) Snow, water, ice and permafrost in the Arctic (SWIPA). AMAP, Oslo

Anders AD, Post E (2006) Distribution-wide effects of climate on population densities of a declining migratory landbird. J Anim Ecol 75:221-227

Anderson TL, Walter JA, Levine TD, Hendricks SP, Johnston KL, White DS, Reuman DC (2018) Using geography to infer the importance of dispersal for the synchrony of freshwater plankton. Oikos 127:403-414

Anderwald P, Herfindal I, Haller RM, Risch AC, Schütz M, Schweiger AK, Filli $F$ (2015) Influence of migratory ungulate management on competitive interactions with resident species in a protected area. Ecosphere 6:art228

Begon M, Townsend CR, Harper JL (2006) Ecology: from individuals to ecosystems, 4th edn. Blackwell Science, Oxford

Benton TG, Lapsley CT, Beckerman AP (2001) Population synchrony and environmental variation: an experimental demonstration. Ecol Lett 4:236-243

Bintanja R, Andry O (2017) Towards a rain-dominated Arctic. Nat Clim Chang 7:263-267

Bjørkvoll E, Grøtan V, Aanes S, Sæther BE, Engen S, Aanes R (2012) Stochastic population dynamics and life-history variation in marine fish species. Am Nat 180:372-387

Bjørnstad ON, Ims RA, Lambin X (1999) Spatial population dynamics: analyzing patterns and processes of population synchrony. Trends Ecol Evol 14:427-432

* Black BA, van der Sleen P, Di Lorenzo E, Griffin D and others (2018) Rising synchrony controls western North American ecosystems. Glob Change Biol 24:2305-2314

* Buckland ST, Newman KB, Fernández C, Thomas L, Harwood J (2007) Embedding population dynamics models in inference. Stat Sci 22:44-58 
Carr MH, Neigel JE, Estes JA, Andelman S, Warner RR, Largier JL (2003) Comparing marine and terrestrial ecosystems: implications for the design of coastal marine reserves. Ecol Appl 13:90-107

Chevalier M, Laffaille P, Ferdy JB, Grenouillet G (2015) Measurements of spatial population synchrony: influence of time series transformations. Oecologia 179:15-28

* Cook CN, Wintle BC, Aldrich SC, Wintle BA (2014) Using strategic foresight to assess conservation opportunity. Conserv Biol 28:1474-1483

Côté SD, Dallas JF, Marshall F, Irvine RJ, Langvatn R, Albon SD (2002) Microsatellite DNA evidence for genetic drift and philopatry in Svalbard reindeer. Mol Ecol 11: 1923-1930

Culina A, Baglioni M, Crowther TW, Visser ME, WoutersenWindhouwer S, Manghi P (2018) Navigating the unfolding open data landscape in ecology and evolution. Nat Ecol Evol 2:420-4262

Culina A, Adriaensen F, Bailey LD, Burgess MD and others (2021) Connecting the data landscape of long-term ecological studies: the SPI-Birds data hub. J Anim Ecol 90: 2147-2160

* Dallas TA, Antão LH, Pöyry J, Leinonen R, Ovaskainen O (2020) Spatial synchrony is related to environmental change in Finnish moth communities. Proc R Soc B 287: 20200684

* Defriez EJ, Sheppard LW, Reid PC, Reuman DC (2016) Climate change-related regime shifts have altered spatial synchrony of plankton dynamics in the North Sea. Glob Change Biol 22:2069-2080

Eberhardt LL (2002) A paradigm for population analysis of long-lived vertebrates. Ecology 83:2841-2854

Elton CS (1924) Periodic fluctuations in the numbers of animals: their causes and effects. J Exp Biol 2:119-163

Engen S (2017) Spatial synchrony and harvesting in fluctuating populations: relaxing the small noise assumption. Theor Popul Biol 116:18-26

Engen S, Sæther BE (2005) Generalizations of the Moran effect explaining spatial synchrony in population fluctuations. Am Nat 166:603-612

Engen S, Cao FJ, Sæther BE (2018a) The effect of harvesting on the spatial synchrony of population fluctuations. Theor Popul Biol 123:28-34

Engen S, Lee AM, Sæther BE (2018b) Spatial distribution and optimal harvesting of an age-structured population in a fluctuating environment. Math Biosci 296:36-44

Forchhammer M, Boertmann D (1993) The muskoxen Ovibos moschatus in north and northeast Greenland: population trends and the influence of abiotic parameters on population dynamics. Ecography 16:299-308

Fretwell SD, Lucas HL (1969) On territorial behavior and other factors influencing habitat distribution in birds. Acta Biotheor 19:16-26

Fuglei E, Henden JA, Callahan CT, Gilg O and others (2020) Circumpolar status of Arctic ptarmigan: population dynamics and trends. Ambio 49:749-761

Gamelon M, Filli F, Sæether BE, Herfindal I (2020) Multi-event capture-recapture analysis in two Alpine chamois populations reveals population-specific responses to interspecific competition. J Anim Ecol 89:2279-2289

Halbritter AH, de Boeck HJ, Eycott AE, Reinsch S and others (2020) The handbook for standardized field and laboratory measurements in terrestrial climate change experiments and observational studies (ClimEx). Methods Ecol Evol 11:22-37
Hamel S, Ims RA, Yoccoz NG (2022) Challenges and opportunities when implementing strategic foresight: lessons learned when engaging stakeholders in climate-ecological research. Clim Res 86:29-35

* Hansen BB, Aanes R, Herfindal I, Kohler J, Sæther BE (2011) Climate, icing, and wild arctic reindeer: past relationships and future prospects. Ecology 92:1917-1923

* Hansen BB, Pedersen ÅØ, Peeters B, Le Moullec M and others (2019) Spatial heterogeneity in climate change effects decouples the long-term dynamics of wild reindeer populations in the high Arctic. Glob Change Biol 25:3656-3668

*Hansen BB, Grøtan V, Herfindal I, Lee AM (2020) The Moran effect revisited: spatial population synchrony under global warming. Ecography 43:1591-1602

Hanski I (1999) Metapopulation ecology. Oxford University Press, Oxford

Keino M, Kaitala V, Ranta E, Lindström J (1997) Synchronous dynamics and rates of extinction in spatially structured populations. Proc Biol Sci 264:481-486

*Henden JA, Ims RA, Yoccoz NG, Killengreen ST (2011) Declining willow ptarmigan populations: the role of habitat structure and community dynamics. Basic Appl Ecol $12: 413-422$

* Henden JA, Ims RA, Fuglei E, Pedersen ÅØ (2017) Changed Arctic-alpine food web interactions under rapid climate warming: implication for ptarmigan research. Wildl Biol 2017:wlb.00240

Henden JA, Ims RA, Yoccoz NG, Asbjørnsen EJ and others (2020) End-user involvement to improve predictions and management of populations with complex dynamics and multiple drivers. Ecol Appl 30:e02120

Henden JA, Ehrich D, Soininen EM, Ims RA (2021) Accounting for food web dynamics when assessing the impact of mesopredator control on declining prey populations. J Appl Ecol 58:104-113

Henden JA, Tveraa T, Stien A, Mellard JP, Marolla F, Ims RA, Yoccoz NG (2022) Direct and indirect effects of environmental drivers on reindeer reproduction. Clim Res 86:179-190

Henriksen S, Hilmo O (eds) (2015) The Norwegian red list of species 2015. Norwegian Biodiversity Information Centre, Trondheim

*Herfindal I, Sæther BE, Solberg EJ, Andersen R, Høgda KA (2006) Population characteristics predict responses in moose body mass to temporal variation in the environment. J Anim Ecol 75:1110-1118

* Herfindal I, Tveraa T, Stien A, Solberg EJ, Grøtan V (2020) When does weather synchronise life history traits? Spatiotemporal patterns in juvenile body mass of two ungulates. J Anim Ecol 89:1419-1432

Herfindal I, Aanes S, Benestad R, Finstad AG, Salthaug A, Stenseth NC, Sæther BE (2022) Spatiotemporal variation in climatic conditions across ecosystems. Clim Res 86: 9-19

*Herrando-Pérez S, Delean S, Brook BW, Bradshaw CJA (2012) Strength of density feedback in census data increases from slow to fast life histories. Ecol Evol 2: 1922-1934

* Hopson J, Fox JW (2019) Occasional long distance dispersal increases spatial synchrony of population cycles. J Anim Ecol 88:154-163

* Ims RA, Andreassen HP (2000) Spatial synchronization of vole population dynamics by predatory birds. Nature 408:194-196 
Ims RA, Yoccoz NG (2017) Ecosystem-based monitoring in the age of rapid climate change and new technologies. Curr Opin Environ Sustain 29:170-176

* Ims RA, Yoccoz NG, Bråthen KA, Fauchald P, Tveraa T, Hausner V (2007) Can reindeer overabundance cause a trophic cascade? Ecosystems 10:607-622

Ims RA, Henden JA, Strømeng MA, Thingnes AV, Garmo MJ, Jepsen JU (2019) Arctic greening and bird nest predation risk across tundra ecotones. Nat Clim Chang 9:607-610

Israelsen MF, Eriksen LF, Moa PF, Hagen BR, Nilsen EB (2020) Survival and cause-specific mortality of harvested willow ptarmigan (Lagopus lagopus) in central Norway. Ecol Evol 10:11144-11154

Jarillo J, Sæther BE, Engen S, Cao FJ (2018) Spatial scales of population synchrony of two competing species: effects of harvesting and strength of competition. Oikos 127: $1459-1470$

Jarillo J, Sæther BE, Engen S, Cao-García FJ (2020) Spatial scales of population synchrony in predator-prey systems. Am Nat 195:216-230

Jonzen N, Lundberg P, Gardmark A (2001) Harvesting spatially distributed populations. Wildl Biol 7:197-203

Kahilainen A, van Nouhuys S, Schulz T, Saastamoinen M (2018) Metapopulation dynamics in a changing climate: increasing spatial synchrony in weather conditions drives metapopulation synchrony of a butterfly inhabiting a fragmented landscape. Glob Change Biol 24:4316-4329

* Kareiva P, Mullen A, Southwood R (1990) Population dynamics in spatially complex environments: theory and data [and discussion]. Philos Trans R Soc B 330:175-190

Kent AD, Yannarell AC, Rusak JA, Triplett EW, McMahon KD (2007) Synchrony in aquatic microbial community dynamics. ISME J 1:38-47

Keymer JE, Marquet PA, Velasco-Hernández JX, Levin SA (2000) Extinction thresholds and metapopulation persistence in dynamic landscapes. Am Nat 156:478-494

Koenig WD (1999) Spatial autocorrelation of ecological phenomena. Trends Ecol Evol 14:22-26

Koenig WD (2001) Spatial autocorrelation and local disappearances in wintering North American birds. Ecology 82:2636-2644

Koenig WD (2002) Global patterns of environmental synchrony and the Moran effect. Ecography 25:283-288

Koenig WD, Liebhold AM (2016) Temporally increasing spatial synchrony of North American temperature and bird populations. Nat Clim Chang 6:614-617

Kuo TC, Mandal S, Yamauchi A, Hsieh CH (2016) Life history traits and exploitation affect the spatial mean-variance relationship in fish abundance. Ecology 97:1251-1259

* Lahoz-Monfort JJ, Morgan BJT, Harris MP, Wanless S, Freeman SN (2011) A capture-recapture model for exploring multi-species synchrony in survival. Methods Ecol Evol 2:116-124

Lande R (1998) Anthropogenic, ecological and genetic factors in extinction and conservation. Res Popul Ecol (Kyoto) 40:259-269

Lande R, Engen S, Sæther BE (1999) Spatial scale of population synchrony: environmental correlation versus dispersal and density regulation. Am Nat 154:271-281

* Lande US, Herfindal I, Willebrand T, Moa PF, Storaas T (2014) Landscape characteristics explain large-scale variation in demographic traits in forest grouse. Landsc Ecol 29:127-139

Layton-Matthews K, Hansen BB, Grøtan V, Fuglei E, Loonen MJJE (2020) Contrasting consequences of climate change for migratory geese: predation, density dependence and carryover effects offset benefits of high-arctic warming. Glob Change Biol 26:642-657

*LLe Moullec M, Buchwal A, Wal R, Sandal L, Hansen BB (2019a) Annual ring growth of a widespread high arctic shrub reflects past fluctuations in community-level plant biomass. J Ecol 107:436-451

Le Moullec M, Pedersen ÅØ, Stien A, Rosvold J, Hansen BB (2019b) A century of conservation: the ongoing recovery of Svalbard reindeer. J Wildl Manag 83:1676-1686

Le Moullec M, Sandal L, Grøtan V, Buchwal A, Hansen BB (2020) Climate synchronises shrub growth across a higharctic archipelago: contrasting implications of summer and winter warming. Oikos 129:1012-1027

Lee AM, Sæther BE (2022) Optimal harvesting in a changing climate. Clim Res 86:21-27

* Lee AM, Sæther BE, Engen S (2020) Spatial covariation of competing species in a fluctuating environment. Ecology 101:e02901

Lee AM, Jarillo J, Peeters B, Hansen BB, Cao-García FJ, Sæther BE, Engen S (2022) Population responses to harvesting in fluctuating environments. Clim Res 86: 79-91

Levin SA (1974) Dispersion and population interactions. Am Nat 108:207-228

Levin SA (1992) The problem of pattern and scale in ecology. Ecology 73:1943-1967

* Liebhold A, Koenig WD, Bjørnstad ON (2004) Spatial synchrony in population dynamics. Annu Rev Ecol Evol Syst 35:467-490

* Lillegård M, Engen S, Sæther BE (2005) Bootstrap methods for estimating spatial synchrony of fluctuating populations. Oikos 109:342-350

* Lindström J (1999) Early development and fitness in birds and mammals. Trends Ecol Evol 14:343-348

* Linnell JDC, Andersen R, Kvam T, Andrén H, Liberg O, Odden J, Moa PF (2001) Home range size and choice of management strategy for lynx in Scandinavia. Environ Manage 27:869-879

MacArthur RH (1972) Geographical ecology. Harper \& Row, New York, NY

Markussen SS, Loison A, Herfindal I, Solberg EJ and others (2018) Fitness correlates of age at primiparity in a hunted moose population. Oecologia 186:447-458

*Markussen SS, Herfindal I, Loison A, Solberg EJ and others (2019) Determinants of age at first reproduction and lifetime breeding success revealed by full paternity assignment in a male ungulate. Oikos 128:328-337

*Marquez JF, Lee AM, Aanes S, Engen S, Herfindal I, Salthaug A, Sæther BE (2019) Spatial scaling of population synchrony in marine fish depends on their life history. Ecol Lett 22:1787-1796

*Marquez JF, Sæther BE, Aanes S, Engen S, Salthaug A, Lee AM (2021) Age-dependent patterns of spatial autocorrelation in fish populations. Ecology 102:e03523

Mellard JP, Henden JA, Pedersen Å, Marolla F, Hamel S, Yoccoz NG, Ims RA (2022) Food web approach for managing arctic wildlife populations in an era of rapid environmental change. Clim Res 86:163-178

*Moran PAP (1953) The statistical analysis of the Canadian lynx cycle. II. Synchronization and meteorology. Aust J Zool 1:291-298

* Myers RA, Mertz G, Barrowman NJ (1995) Spatial scales of variability in cod recruitment in the North Atlantic. Can J Fish Aquat Sci 52:1849-1862 
Myers RA, Mertz G, Bridson J (1997) Spatial scales of interannual recruitment variations of marine, anadromous, and freshwater fish. Can J Fish Aquat Sci 54:1400-1407

Myers-Smith IH, Elmendorf SC, Beck PSA, Wilmking M and others (2015) Climate sensitivity of shrub growth across the tundra biome. Nat Clim Chang 5:887-891

Mysterud A (2006) The concept of overgrazing and its role in management of large herbivores. Wildl Biol 12:129-141

* Mysterud A, Langvatn R, Yoccoz NG, Stenseth NC (2001) Plant phenology, migration and geographical variation in body weight of a large herbivore: the effect of a variable topography. J Anim Ecol 70:915-923

Mysterud A, Langvatn R, Yoccoz NG, Stenseth NC (2002) Large-scale habitat variability, delayed density effects and red deer populations in Norway. J Anim Ecol 71:569-580

Negret PJ, Di Marco M, Sonter LJ, Rhodes J, Possingham HP, Maron M (2020) Effects of spatial autocorrelation and sampling design on estimates of protected area effectiveness. Conserv Biol 34:1452-1462

Nielsen A, Yoccoz NG, Steinheim G, Storvik GO and others (2012) Are responses of herbivores to environmental variability spatially consistent in alpine ecosystems? Glob Change Biol 18:3050-3062

* Pandit SN, Cottenie K, Enders EC, Kolasa J (2016) The role of local and regional processes on population synchrony along the gradients of habitat specialization. Ecosphere 7:e01217

Paradis E, Baillie SR, Sutherland WJ, Dudley C, Crick HQP, Gregory RD (2000a) Large-scale spatial variation in the breeding performance of song thrushes Turdus philomelos and blackbirds T. merula in Britain. J Appl Ecol 37:73-87

* Paradis E, Baillie SR, Sutherland WJ, Gregory RD (2000b) Spatial synchrony in populations of birds: effects of habitat, population trend, and spatial scale. Ecology 81: 2112-2125

*Pascual M, Levin SA (1999) Spatial scaling in a benthic population model with density-dependent disturbance. Theor Popul Biol 56:106-122

* Peeters B, Pedersen ÅØ, Loe LE, Isaksen K and others (2019) Spatiotemporal patterns of rain-on-snow and basal ice in high Arctic Svalbard: detection of a climate-cryosphere regime shift. Environ Res Lett 14:015002

Peeters B, Le Moullec M, Raeymaekers JAM, Marquez JF and others (2020) Sea ice loss increases genetic isolation in a high Arctic ungulate metapopulation. Glob Change Biol 26:2028-2041

Péron G, Ferrand Y, Choquet R, Pradel R and others (2012) Spatial heterogeneity in mortality and its impact on the population dynamics of Eurasian woodcocks. Popul Ecol 54:305-312

* Pigeon G, Loe LE, Bischof R, Bonenfant C and others (2019) Silver spoon effects are constrained under extreme adult environmental conditions. Ecology 100:e02886

* Post E, Bhatt US, Bitz CM, Brodie JF and others (2013) Ecological consequences of sea-ice decline. Science 341 : 519-524

Putkonen J, Roe G (2003) Rain-on-snow events impact soil temperatures and affect ungulate survival. Geophys Res Lett 30:1188

Ranta E, Kaitala V, Lundberg P (1997) The spatial dimension in population fluctuations. Science 278:1621-1623

Ranta E, Kaitala V, Lundberg P (1999) Synchronicity in population systems: cause and consequences mixed. Trends Ecol Evol 14:400-401
Ranta E, Lindström J, Lindén H, Helle P (2008) How reliable are harvesting data for analyses of spatio-temporal population dynamics? Oikos 117:1461-1468

Redpath SM, Young J, Evely A, Adams WM and others (2013) Understanding and managing conservation conflicts. Trends Ecol Evol 28:100-109

Robertson GS, Bolton M, Morrison P, Monaghan P (2015) Variation in population synchrony in a multi-species seabird community: response to changes in predator abundance. PLOS ONE 10:e0131543

Royama T (1992) Analytical population dynamics. Chapman \& Hall, London

* Saccheri I, Kuussaari M, Kankare M, Vikman P, Fortelius W, Hanski I (1998) Inbreeding and extinction in a butterfly metapopulation. Nature 392:491-494

* Sæther BE, Engen S, Grøtan V, Fiedler W and others (2007) The extended Moran effect and large-scale synchronous fluctuations in the size of great tit and blue tit populations. J Anim Ecol 76:315-325

Solberg EJ, Rolandsen CM, Heim M, Grøtan V and others (2006) Moose in Norway. An analysis of material collected by moose hunters 1966-2004. NINA Report 125, Norwegian Institute for Nature Research, Trondheim (in Norwegian with English summary)

Steele JH (1985) A comparison of terrestrial and marine ecological systems. Nature 313:355-358

* Steele JH, Henderson EW (1994) Coupling between physical and biological scales. Philos Trans R Soc B 343:5-9

* Stenseth NC, Mysterud A, Ottersen G, Hurrell JW, Chan KS, Lima M (2002) Ecological effects of climate fluctuations. Science 297:1292-1296

Stien A, Ims RA, Albon SD, Fuglei E and others (2012) Congruent responses to weather variability in high arctic herbivores. Biol Lett 8:1002-1005

พ Tveraa T, Stien A, Bårdsen BJ, Fauchald P (2013) Population densities, vegetation green-up, and plant productivity: impacts on reproductive success and juvenile body mass in reindeer. PLOS ONE 8:e56450

Tyler NJC (1987) Natural limitation of the abundance of the high arctic Svalbard reindeer. PhD thesis, University of Cambridge

*van de Pol M, Cockburn A (2011) Identifying the critical climatic time window that affects trait expression. Am Nat 177:698-707

* van der Wal R, Stien A (2014) High-arctic plants like it hot: a long-term investigation of between-year variability in plant biomass. Ecology 95:3414-3427

*Vindstad OPL, Jepsen JU, Yoccoz NG, Bjørnstad ON, Mesquita MDS, Ims RA (2019) Spatial synchrony in sub-arctic geometrid moth outbreaks reflects dispersal in larval and adult life cycle stages. J Anim Ecol 88: 1134-1145

*Walter JA, Sheppard LW, Anderson TL, Kastens JH, Bjørnstad ON, Liebhold AM, Reuman DC (2017) The geography of spatial synchrony. Ecol Lett 20:801-814

Wiens JA (1989) Spatial scaling in ecology. Funct Ecol 3: 385-397

Yoccoz NG, Nichols JD, Boulinier T (2001) Monitoring of biological diversity in space and time. Trends Ecol Evol 16:446-453

Zannése A, Morellet N, Targhetta C, Coulon A, Fuser S, Hewison AJM, Ramanzin M (2006) Spatial structure of roe deer populations: towards defining management units at a landscape scale. J Appl Ecol 43:1087-1097 